\title{
Sustainability of combustion and incineration of renewable fuels: example of Sweden
}

\author{
R. Sjöblom ${ }^{1,2}$ \\ ${ }^{1}$ Waste Science and Technology, Luleå University of Technology, Sweden \\ ${ }^{2}$ Tekedo AB, Sweden
}

\begin{abstract}
According to the statistics at the EC Commission, Sweden is the Champion by far in Europe in terms of renewable energy. It comprised around $45 \%$ of the total in the year 2008. This position has been reached by a combination of natural resources, political determination and technology development.

A major contributor to this is the extensive utilization of district heating which amounts to around $50 \mathrm{TWh}$ per year, and which covers about half of the total need for industrial and domestic buildings. The district heating is based mainly on combustion of bio fuels together with waste and some peat.

This practice is generally very positive from a sustainability perspective for the following reasons: (1) bio fuels are renewable, and so is peat, although over a longer time span; (2) waste is being recovered for energy purposes; and (3) ash material is, in many cases, re-circulated and recycled.

However, sustainability is not only about total percentages, but also on the quality in the processes, especially in terms of qualification of fuels and ashes and the associated possibilities for more efficient combustion and incineration processes as well as ash utilization. Efficiency in this regard of course also includes protection of health and the environment. These aspects are explored in a technical as well as a legal perspective, and some possibilities for further development and improvement are identified and discussed.

The compilation and analyses are based on more than ten years of research reports (mostly in Swedish) financed by District Heating in Sweden (Svensk Fjärrvärme), [The Swedish] Thermal Engineering Research Institute (Värmeforsk), the Swedish Waste Management (Avfall Sverige) and Svenska Energiaskor AB (which translates to: "Swedish Energy Ashes Inc.").

Keywords: sustainable, combustion, incineration, bio fuels, waste, ash, Sweden.
\end{abstract}




\section{Introduction, purpose and objective}

\subsection{Introduction}

It might be tempting to assume that energy from renewable sources in general, and not least thermo-chemical energy, is sustainable by definition. Nonetheless, energy beneficiation, however renewable, would still not be sustainable, at least not entirely, if it were associated with - especially permanent - detriment to health and the environment and/or the consumption of limited resources other than energy resources.

Moreover, since renewable energy can usually replace non-renewable energy resources, it is also essential with regard to sustainability that the utilization is efficient.

Flow of matter and energy, such as is the case in combustion and incineration, might be referred to as metabolism, and such a system might be considered as part of the anthroposphere [1]. Thus, when sustainability is to be assessed, it is the complete system from preparation of the fuel to and including the beneficiation or disposal of the ash that needs to be analysed.

The performance of such a process system is quite complex and has been the subject of intense research and development for the last couple of decades by many researchers and engineers and through financing by many entities, including branch research organizations (see Acknowledgements).

Moreover, the process system has undergone far-reaching changes over the same period of time. As will be dealt with further in Section 4, most of the waste is nowadays sorted and recycled, whilst most of it was just land-filled as received twenty years ago.

External prerequisites for the process system have also changed substantially. Residues may nowadays in certain cases be regarded as by-products, and waste might be recycled to become products. For products, a novel EC regulation applies - REACH.

\subsection{Purpose and objective}

Obviously, some complex but important relations exist in the process system just described, several of which are closely related to sustainability.

The purpose of the present work is to describe such features and to discuss different alternatives and their implications. The analyses and the conclusions are to be based on brief compilations of the following:

- a brief background on thermo-chemical energy from renewable sources in Sweden in a European perspective,

- $\quad$ some legal aspects including the differentiation between waste and products, and

- $\quad$ some relations between fuel quality, furnace, flue gas cleaning and ash.

Classification of ash under the EC directive of waste has been dealt with in [2], and such evaluations also form the basis for assessment of the suitability of ash for various purposes and destinations. Work is in progress on utilization of 
ash for remediation of mine tailings rich in sulfides as well as on sorting of waste before combustion and incineration, and those results will be published later. The analyses in the present paper focus on qualification of fuel as waste or as a product together with the associated prerequisites for combustion and incineration.

\section{Thermo-chemical renewable energy utilization in Sweden}

According to the Internet page of the Government Agency Statistics Sweden, Sweden had a population of 9555893 inhabitants at the end of the year 2012, corresponding to a population density of 18 inhabitants per square kilometre.

The climate is cold and the industry is rather energy intensive, and so the energy generation and consumption is high (see Figure 1).

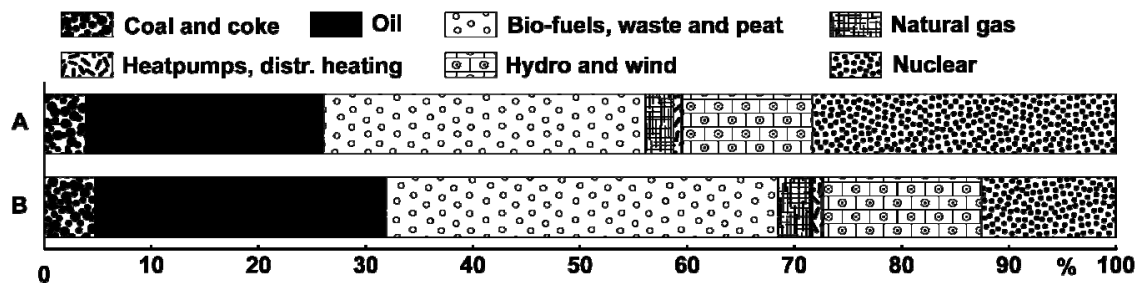

Figure 1: Energy input in Sweden for the year 2011. Alternative A refers to nuclear energy figured as total heat and corresponds to $62 \mathrm{MWh}$ per capita. Alternative B is based on nuclear energy figured as electricity output, and this corresponds to $50 \mathrm{MWh}$ per capita.

As can be seen in the Figure, Sweden is high in nuclear electric energy generation, and actually Champion in the World with $6.4 \mathrm{MWh}$ per capita. The sustainability of nuclear energy with regard to decommissioning and waste management is dealt with in Reference [4].

However, the present paper focuses on the biofuels, waste and peat portions in Figure 1. According to Reference [5], Annex 1, the share of energy from renewable sources in gross final consumption was $39.8 \%$ in the year 2005 , more than $7 \%$ more than Latvia and Finland which were second and third, respectively within the EC. The share has increased since, and the goal is to reach $49 \%$ by the year 2020 [5].

According to the statistics published at the web page of District Heating in Sweden (Svensk Fjärrvärme), a total of $57.0 \mathrm{TWh}$ was delivered as heat and 8.4 TWh as electricity from our district heating facilities in the year 2011. This corresponds to 6.0 and $0.9 \mathrm{MWh}$ per capita, respectively. District heating accounts for about half of the domestic heating in Sweden. The contributions from various sources are shown in Figure 2. 


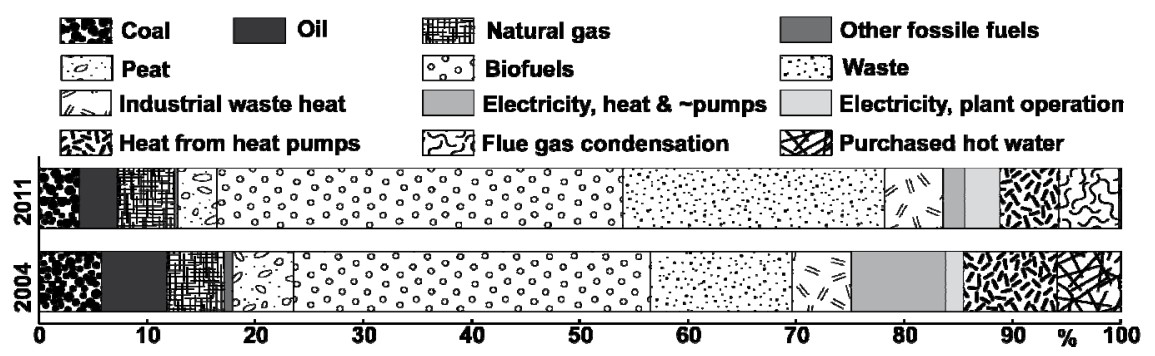

Figure 2: The contributions from the various sources for the heat and electricity supplied by the district heating plants in Sweden.

The efficiency in the heat production is $97 \%$, not including the flue gas condensation. The efficiency is somewhat lower for electricity generation since other sinks apart from the district heating grids may sometimes be used for condensation of the steam e. g. in the summer when the need for heat is low. The high efficiency includes the incineration of waste.

Each year, the Swedish Waste Management (Avfall Sverige) publishes a report with statistics on the waste management [6]. Detailed data is provided on the emissions from the incineration facilities, and it is found that they are well within the legal limits and the various permits. All incineration in Sweden constitutes energy recovery of the waste as it is defined in Annex II of the EC Waste Directive [7].

In the year 2011, a total of 2.2 million tons of domestic waste and about 3 million tons of other waste was incinerated, generating a total of $13.5 \mathrm{TWh}$ of heat and 2 TWh of electricity.

Ashes from combustion and incineration exit at different points in the facilities and in different forms, and this renders them somewhat difficult to categorize. It should be observed that the ash content of different fuels may vary considerably. It may be as low as $0.5 \%$ in stem wood and as high as $30 \%$ in domestic waste. The annual total generation of ash, including district heating, wood and the paper and pulp industry has been estimated to 1.48 million tons [8].

Avfall Sverige reports [6] that 880 thousand tons of bottom ash and 257 thousand tons of fly ash are generated from incineration of waste. Most of the bottom ash is used for covers of landfills while most of the fly ash is hazardous waste which is either deposited in landfills or sent abroad for stabilization. This is in concordance with the experience of the present author who has analyzed and classified ashes from more than two thirds of the incineration furnaces [2].

According to [8], only $2 \%$ of all the ash generated is returned to the forest as a nutrient.

Landfilling in Sweden has decreased from 6.08 million tons in the year 1994 to only 1.52 in 2011 [6]. This implies that the need for ash for covers of landfills will decrease accordingly. 


\section{Legal aspects}

\subsection{Legislation}

Legislation in Sweden comprises three levels: laws, ordinances and regulations. They are issued by parliament, government and regulatory authorities, respectively. Some issues are covered by EC regulations, and they are directly applicable in Sweden. EC directives have concomitant national legislation. In the following, the directive corresponding to the national legislation in question will be discussed for simplicity.

\subsubsection{Some general considerations in the Swedish environmental code}

The Swedish environmental legislation is regulated in a comprehensive manner by the Swedish environmental code [9]. Some "general rules of consideration" are presented in Table 1. The following is of particular interest in the present context:

Table 1: $\quad$ Some general rules of consideration from chapter 2 in the Swedish environmental code [9].

\begin{tabular}{|l|l|}
\hline Section 2 & $\begin{array}{l}\text { "Persons who pursue an activity or take a measure, or intend to } \\
\text { do so, shall implement protective measures, comply with } \\
\text { restrictions and take any other precautions that are necessary in } \\
\text { order to prevent, hinder or combat damage or detriment to human } \\
\text { health or the environment ...". }\end{array}$ \\
\hline Section 3 & $\begin{array}{l}\text { "Persons who pursue an activity or take a measure, or intend to } \\
\text { do so, shall implement protective measures, comply with } \\
\text { restrictions and take any other precautions that are necessary in } \\
\text { order to prevent, hinder or combat damage or detriment to human } \\
\text { health or the environment ...". }\end{array}$ \\
\hline Section 3 & "... the best possible technology shall be used ...". \\
\hline Section 5 & $\begin{array}{l}\text { "Persons ... shall conserve raw materials and energy and reuse } \\
\text { and recycle them wherever possible. Preference shall be given to } \\
\text { renewable energy sources." }\end{array}$ \\
\hline
\end{tabular}

\subsubsection{The Swedish environmental code and the waste framework directive}

Some of the content of the EC waste framework directive [7] is implemented in chapter 15 of the Swedish environmental code [9], including the following.

Article 5 of the EC waste framework directive [7] states when a production residue is a by-product and not waste:

"(a) further use of the substance or object is certain;

(b) the substance or object can be used directly without any further processing other than normal industrial practice;

(c) the substance or object is produced as an integral part of a production process; and

(d) further use is lawful ..." 
Article 6 of the EC waste framework directive [7] states when waste has become a product:

"(a) the substance or object is commonly used for specific purposes;

(b) a market or demand exists for such a substance or object;

(c) the substance or object fulfils the technical requirements for the specific purposes and meets the existing legislation and standards applicable to products; and

(d) the use of the substance or object will not lead to overall adverse environmental or human health impacts."

\subsubsection{Environmentally hazardous activities}

The ordinance (SFS 1998-899) concerning environmentally hazardous activities and the protection of public health regulates when reporting and applications for permits are required. In general, this is required for combustion and incineration facilities with a capacity exceeding $0.5 \mathrm{MW}$. It should be noted that the lowest level, reporting to the municipal board, includes the option for the board to forward the matter to higher instances.

\subsubsection{Combustion and incineration}

Incineration of waste as well as mixtures of waste and fuel products is carried out under the incineration directive [10]. The corresponding Swedish legislation includes the ordinance SFS 2002:1060 together with the regulations NFS 2002:26 and NFS 2002:28. They contain limits on releases together with requirements on continuous as well as recurrent monitoring for fuel that is waste as well as products.

The legislation is intended to ensure that limits on emissions are not to be exceeded even in cases where there are considerable variations in the composition of the fuel. The protection is accomplished through the concerted effect of the legislation just mentioned together with the permit issued in concordance with SFS 1998-899 (see Section 3.1.3) which includes data on the flue gas cleaning system and a list of fuel types to be used.

\subsubsection{Ongoing work at the EC Commission}

It has not escaped the attention of the EC Commission that there is a difference in degree of detail in the legislations on combustion of fuels that are products and that on incineration of waste. In concordance, the Commission has commissioned its Joint Research Centre to investigate the issue. It is the intention that the results will form the basis for new regulations. The Centre has, in turn, contracted work to the Environment Agency Austria who have published an interim report [11].

The report finds that the emission limits under the waste directive are stricter than what may apply for non-waste, and thus some further specification for the fuel is warranted in the latter case.

The report concludes that "product and end-of-waste standards/specification already exist or will be developed ...": for the following: biogas, biodiesel and bio-ethanol. It also finds that end-of-waste criteria should be possible to obtain for e. g. wood and plastics. 
The report finds that "In case such criteria for the end-of-waste status have not been set at community level, Member States may decide case-by-case whether certain waste has ceased to be waste, taking into account the applicable case law." Such an attempt is described in the subsequent section.

\subsection{Court cases}

Two court cases have been found which relate to the question of waste or product: case M 585-08 on combustion of a filter medium, and M7546-08 on a residue from reprocessing of paper. Both were settled at our highest environmental court, Svea Court of Appeal, the Land and Environmental Court unit. Only the latter case will be described in the following.

The issue was dealt with consecutively at the County Administration Board at Västerbotten, the Land and Environmental Court at Umeå, and the Svea Court of Appeal. The courts were supported by expertise statements issued by the Swedish Environmental Protection Agency (EPA). The court decisions were essentially the same in all of the rulings.

Court documents in Sweden are (with few exceptions) open to the public, and the acts in question have been analyzed for the purpose of the present work. However, only those aspects of the case that are relevant for the purpose of the present paper are summarized in the following.

The company, SCA Packaging Ubbola AB, intended to burn the residue together with bark in its furnace on site. Formally, bark is regarded as waste (at least in the EPA statement), but it is exempted from the rules on incineration. The main issue was whether or not the residue, containing about $30 \%$ of plastics, should be considered as waste.

The lawyer representing the company focused on the rulings in the Court of Justice of the EC, and not as much on the technical issues as did the County Administration Board supported by EPA. The latter maintained that the plastic residue contains heavy metals as well as chlorine which is a known promoter of dioxin formation. No real attempts were made by the lawyer to prove that classification of the residue as a product, under the specifications by the company, and under the legislation of the environmental code (see Section 3.1.1) and some other legislation such as CLP and REACH, would render at least as good a protection of health and environment as would be the case under the legislation on incineration.

Conversely, the EPA pointed out that classification as a product would provide no legal obstacle for the supervisory authority to prescribe whatever precautionary measures that it might find appropriate.

The ruling was that the residue is waste, and the company had to install the monitoring equipment required under the legislation on incineration. 


\section{Metabolism of combustion and incineration}

\subsection{Introduction}

Modern systems and processes for combustion and incineration of renewable fuels are very complex and conditions vary considerably with regard to e. g. fuel, furnace design, flue gas cleaning, ash management, type of production (heat or heat and electricity), and load characteristics (base or peak load).

In concordance, all these areas have been the subject of intensive research and development activities at the plants, in collective branch research programs and at universities. The domestic work published during the last ten years or more has been reviewed for the purpose of the present work. However, only very brief summaries of some important facts and findings are given in the following, in most cases without references. The author hopes to return to this issue in a future publication.

\subsection{The metabolism of combustion and incineration processes}

Basic and general descriptions of combustion and incineration processes can be found in $[12,13]$. Three different furnace types are used: grate fired systems, fluidized bed systems and furnaces with powder burners. Ash is collected as fly ash and bottom ash except for powder burners that generate only fly ash.

Furnace systems together with operation parameters are chosen such that all combustible material is oxidized and that all burnable contaminants (substances that may be detrimental to health and the environment) become destroyed. This implies e. g. that temperatures be kept higher and times longer for incineration of fuels containing certain very stable chlorinated compounds. Incomplete combustion can also lead to formation of poly-aromatic hydrocarbons (PAH).

In some cases, dioxins can form, and the following parameters promote such generation: long time at intermediate temperature, presence of chlorine, presence of transition metals, and incomplete combustion. Modern furnaces operating with conditions unfavorable with regard to dioxin generation produce only very low levels. Moreover, if dioxin levels are low, so are usually also those for PAH.

Chlorine associates to other elements somewhat differently at different temperatures and depending on the water content. It readily associates itself with potassium and sodium as well as with calcium, but also with e. g. zinc and lead thus rendering them much more volatile than would otherwise have been the case. The latter elements can therefore cause problems in terms of scale on the tubes as well as high leach rates in the ash, at least before they are hydrolyzed and incorporated into other phases. Chlorine that is not balanced by metallic elements as just described leaves the furnace in the form of hydrochloric acid vapor. Only limited levels of this compound may be released and therefore hydrochloric acid may have to be removed either by wet scrubbing or flue gas condensation (or both).

The metabolism of sulfur is somewhat more complex since sulfur has the valence six at low temperatures and that of four at high. Consequently, sulfur 
dioxide has a tendency to oxidize at lower temperatures, but the reaction is inefficient in the gas phase and is much more rapid on surfaces containing oxides of certain transition metals. This implies that chlorides deposited on the surfaces of tubes are converted to hydrochloric acid as incoming sulfur dioxide is oxidized and this acid may cause corrosion on the surfaces of the tubes. There are limits on emissions of sulfur dioxide and therefore it may have to be removed by semi-dry or wet scrubbing. Flue gas condensation is usually not sufficient.

It is not only the absolute levels of sulfur and chlorine that is of interest, but also their relative abundance. Chlorides usually have comparatively low melting points and do not dissolve much of oxides. They do, however mix with sulfates, which have somewhat higher melting temperatures. Mixtures of chlorides and sulfates with moderately high chlorine to sulfur ratios melt at even lower temperatures than the corresponding chlorides. Consequently, the chlorine to sulfur levels are often kept sufficiently low in order to avoid scale formation.

In practice, this may mean that a fuel rich in chloride, such as domestic waste, may be mixed with some other fuel rich in sulfur, e. g. sewage sludge.

Transition metals and heavy metals are distributed between bottom ash and fly ash in relation to their volatility under combustion conditions. Most of these elements are enriched in the fly ash, but to a very varying degree.

For the most part, transition and heavy elements are efficiently removed by electrostatic filters and/or mechanical filters (or other filters with similar capability). This may not be the case, however, for certain very volatile elements, especially mercury, but also cadmium. Mercury might therefore have to be absorbed by active carbon.

The following elements are of particular interest with regard to the health and environment related properties of the ash: arsenic, antimony, lead, chromium, molybdenum, nickel and zinc. In many cases, chromium, nickel and zinc may be or become self-stabilized in the ash by solid solution in iron-rich phases [2].

Different fuels have different contents of these elements. For instance, most of the arsenic in the ash originates from CCA-impregnated wood (CCA = Copper, Chromium and Arsenic) and can appear in recycled wood. Lead may be associated with old paint and plastics and may be present in domestic waste as well as recycled wood.

Fuels of interest include animal waste, domestic waste, paper, peat, plastics and rubber, pure vegetable fuels, recycled wood, residues from the pulp and paper industries, sewage sludge and tall oil.

It is a prerequisite for efficient and qualified ash utilization that contaminants be concentrated in a portion of the ash. This can be achieved by a combination of efficient sorting of the fuel together with careful selection of the fuels to be used at the various facilities.

\section{Discussion and conclusions}

A system for thermo-chemical energy from renewable sources should be characterized by the following:

1 protection of health and the environment 
2 sustainable with regard to

(a) the fuels that should be renewable

(b) the substances exiting the system that should as far as is possible and reasonable be reused and re-circulated in the anthroposphere

3 efficient and cost effective

Protection of health and the environment is an absolute prerequisite. Legislation must be followed to letter and should be followed also to intent. Efficiency and cost effectiveness are necessary in order for an activity to be feasible and possible to carry out.

As can be seen from Section 4.2 above, most of the fuels can be regarded as sustainable. This includes domestic waste and industrial miscellaneous waste where most of the heat comes from wood, either directly or in the form of paper. However, domestic waste also contains plastics, and the level of fossil carbon has been estimated to $12.6 \%$ by weight [14]. However, actual measurements of the content of carbon-14 in the waste carried out by Renova in Gothenburg indicate a level of only around $2 \%$.

It should be considered when the sustainability of incineration is to be assessed that the practice implies that the vast majority of potentially harmful substances in the waste are destroyed. Economically, the value of the destruction corresponds approximately to the cost of virgin fuel of the same calorific value.

This should be kept in mind also when the waste hierarchy in the EC waste directive (Article 4) [7] is being considered. In addition to the destruction of potentially harmful substances, incineration also reduces volume, and often converts the waste to a form suitable for recycling or disposal.

Actually, the sustainability of the metabolism of matter in incineration and combustion systems depends on a number of factors. It is not only the figure for total utilization that should be used, but also quality factors for the various uses. For instance, merely choosing ash for preparing the surface of the waste in a landfill before applying the seal of a cover is a comparatively unqualified use for which even quite contaminated ash is feasible. Utilization in a cover or in a road requires low contents of contaminants together with specific desirable materials properties. Conversely, it is important to find applications in which also elevated levels of contaminants pose no threat to health and the environment.

The possibilities for utilization of ash depend on the chemical and physical properties as well as the levels of contaminants, but the bottleneck is usually the latter, especially the levels of elements like lead, arsenic, antimony, zinc, chromium, molybdenum, nickel, etc. It is not only their levels that are of interest but also their chemical form, and this has been dealt with in a previous publication [2].

The contaminants are not evenly distributed between the various waste streams, and to some extent the latter can be separated into streams with different levels of contaminants before incineration. On the other hand, mixing different streams of waste is often favorable for the combustion process and may lead to less favorable concentrations of contaminants from an ash recycling perspective.

If waste could be sorted to near virgin fuel quality, then the corresponding ash would be easier to utilize in a qualified manner. Such a comparison with virgin 
material is not a formal requirement (although frequently put forward such as was done in the case M7546-08, see Section 3.2). Nonetheless, such an approach makes good sense since it lowers the threshold for use of fuel as a product. Some fuels do not have a corresponding virgin fuel, e. g. plastics, but it is feasible to develop corresponding standards also in such cases.

The option to classify fuel as a product as presented in Section 3.1.2 increases the degrees of freedom for the companies and thereby also the possibilities for achieving and improving sustainability.

On its Internet page, the Svea Court of Appeal includes the court case M7546-08 in a listing of cases that are important precedents. It is obvious from Section 3.2 that this includes that health and environment has to be protected to the satisfaction of the Authorities and the Courts regardless of whether the fuel is waste or a product. Classification of fuels as products should thus not be attempted as any easy fix to avoid responsibility.

The ruling should not, however, be interpreted to imply that classification as a product in accordance with Section 3.1.2 above is not possible in Sweden. Instead it is for the owners and operators of the facilities to decide whether they chose to go ahead with such classification now or if they prefer to await the further developments at the EC Commission. This conclusion is in concordance with the following statement in [11]:

"In the current absence of EU-wide end-of-waste criteria [for specific waste types], Member States may decide case by case whether certain waste has ceased to be waste taking into account the applicable case law."

For such case-by-case classification it is important to realize that the legislation on waste incineration rests on a comprehensive knowledge base, and that adequate proof will have to be provided in the case of classification as a product, e. g. on variations together with quality control and assurance.

It is concluded that Sweden is Champion, at least in Europe, on the utilization of renewable energy, and that this practice is also sustainable. However, the systems are complex and improvements are possible with regard to the utilization of substances exiting the system. This requires amongst other things further integration between the different areas of expertise: fuel, combustion and ash utilization, as well as between lawyers, engineers and scientists.

\section{Acknowledgements}

The present work is based on more than ten years of research reports (mostly in Swedish) financed by District Heating in Sweden (Svensk Fjärrvärme), [The Swedish] Thermal Engineering Research Institute (Värmeforsk), the Swedish Waste Management (Avfall Sverige) and Svenska Energiaskor AB (which translates to: "Swedish Energy Ashes Inc.").

Much of the present analyses have been made as a part of a recent commission from District Heating in Sweden. It was carried out in collaboration with Signe Lagerkvist who is a Lecturer at the Department of Law at Umea University, and who is also affiliated to the Land and Environment Court at the Umeå District Court. Her expert input is highly appreciated. 


\section{References}

[1] Baccini, P. and Brunner, P. H., Metabolism of the anthroposphere: analysis, evaluation, design. MIT Press, 2nd edition, 2012.

[2] Sjöblom, R., Classification of waste as hazardous or non-hazardous - the cases of ash and slag. WIT Transactions on Ecology and The Environment, Vol. 163, pp. 285-296, 2012.

[3] Annual Energy Balance Sheets 2010 - 2011. Statistics Sweden, Statistiska meddelanden, EN 20 SM 1206, korrigerad version, December 2012. Published on commission by the Swedish Energy Agency.

[4] Lindskog, S, Labor, B. and Sjöblom, R., Sustainability of nuclear energy with regard to decommissioning and waste management. International Journal of Sustainable Development and Planning, in print.

[5] Directive 2009/28/EC of the European Parliament and of the Council of 23 April 2009 on the promotion of the use of energy from renewable sources.

[6] Swedish Waste Management 2012. Available at www.avfallsverige.se.

[7] Directive 2008/98/EC of the European Parliament and of the Council of 19 November 2008 on waste and repealing certain Directives.

[8] Ashes in Sweden 2010 (Swedish title: Askor i Sverige 2010). Published by Svenska Energiaskor AB and available at www.energiaskor.se.

[9] The Swedish Environmental code (translation of SFS 1998:808, not updated). Available at http://www.government.se/sb/d/2023/a/22847.

[10] Directive 2000/76/EC of the European Parliament and of the Council of 4 December 2000 on the incineration of waste.

[11] Stoiber, H., project manager (many authors), Study on the suitability of the different waste-derived fuels for end-of-waste status in accordance with article 6 of the waste framework directive, second interim report. Draft for consultation. Environment Agency Austria, Vienna, August 2011.

[12] Raask, E., Mineral impurities in coal combustion behavior, problems, and remedial measures. Hemisphere Pub. Corp. in Washington, 1985.

[13] Chandler, A. J., Eighmy, T. T., Hartlén, J., Hjelmar, O., Kosson, D. S., Sawell, S. E., Van der Sloot, H. A. and Vehlow, J., Municipal solid waste incinerator residues. Elsevier Science B.V. 1997.

[14] Sundqvist, J.-O., Evaluation of Swedish waste policy in a system perspective. (Swedish title: Utvärdering av svensk avfallspolitik i ett systemperspektiv). Swedish Waste Management (Avfall Sverige) Report 2007:10. 